\title{
Effect of Sucrose Fatty Acid Esters on Transdermal Permeation of Lidocaine and Ketoprofen
}

\author{
Hirokazu Oкамото, * Takashi SAKaI, and Kazumi Danjo \\ Faculty of Pharmacy, Meijo University; 150 Yagotoyama Tempaku-ku, Nagoya 468-8503, Japan.
} Received February 17, 2005; accepted June 6, 2005; published online June 22, 2005

\begin{abstract}
The effect of sucrose fatty acid esters on transdermal permeation of lidocaine (LC) and ketoprofen was examined. A drug solution was applied to excised hairless mouse skin pretreated with a sugar ester solution to examine the direct effects of the sugar esters on skin permeability. LC was applied with a pH 6 buffer solution (98.8\% ionized), pH 10 buffer solution (99.2\% unionized), or propylene glycol, while KP was applied with a pH 6 buffer solution (99.1\% ionized), pH 2 buffer solution (98.9\% unionized), or propylene glycol. Pretreatment with $\mathrm{J}-1216$ (sucrose laurate, HLB=16) or $\mathrm{J}-1205$ (sucrose laurate, HLB=5) significantly increased the permeation of LC from the pH 6 solution and KP from propylene glycol, respectively. The permeability coefficients of the ionized and unionized LC and KP were calculated from the permeability data. The ionized LC and KP permeated even through skin not pretreated with sugar esters, although the permeability coefficients were 24 times and 38 times less than those of the unionized LC and KP, respectively. J-1216 pretreatment increased the permeability of ionized LC from aqueous vehicle 2.7 fold. In the next series of experiments, we formulated $1.5 \%$ of $\mathrm{J}-1205$ and $\mathrm{J}$ 1216 in various vehicles to examine their effect on the permeation of $L C$ applied on the excised hairless mouse skin with no pretreatment. The results coincided with the results of the pretreatment experiment, and the effect of J-1205 in propylene glycol was more remarkable than that observed in the pretreatment study. When these sugar esters were dissolved in propylene glycol at $1.5 \%, \mathrm{~J}-1205$ increased significantly the KP permeation rate as well as LC permeation rate, suggesting that the combination of $\mathrm{J}-1205$ and propylene glycol would be a potent vehicle for transdermal formulations.
\end{abstract}

Key words sucrose fatty acid ester; percutaneous absorption enhancer; permeability; lidocaine; ketoprofen

Skin has many advantages as a site for local and systemic drug administration. However, the barrier properties of the outermost layer, the stratum corneum, have limited the number of successful transdermal dosage forms developed thus far. One of the strategies for overcoming this problem is temporary local reduction of the barrier function of the stratum corneum with the aid of a percutaneous absorption enhancer.

Sucrose fatty acid esters (sugar esters) are nonionic surfactants with sucrose as the polar head group and one or several fatty acid chains as the lipophilic moiety. Some of them are legally approved as food additives due to their high safety ${ }^{1)}$ and are registered as pharmaceutical excipients in Japan, USA, Canada, Australia, and New Zeeland. ${ }^{2)}$ Sugar esters have low irritancy to the skin and eyes. ${ }^{1)}$

There have been several reports or patents about utilizing sugar esters as additives for drug formulations. Some sugar esters enhance gastrointestinal absorption of elastase ${ }^{3)}$ and $\beta$ lactam antibiotics. ${ }^{4)}$ The nasal mucosal absorption of peptides such as calcitonin, ${ }^{5)}$ interferon, ${ }^{6}$ and $\alpha$-human atrial natriuretic polypeptide ${ }^{7)}$ are increased by sucrose laurate or sucrose stearate. Sucrose palmitate enhances the absorption of calcitonin from the oral mucosa ${ }^{8)}$ and gingiva ${ }^{9)}$ in rats. Ganem-Quintanar et al. examined the effect of sucrose stearate, oleate, palmitate, and laurate on the permeation of lidocaine hydrochloride through excised pig palate and cheek and reported that only sucrose laurate acted as an absorption enhancer. ${ }^{10)}$ Some sugar esters act as percutaneous absorption enhancers. It has been reported that sucrose stearate and sucrose laurate increase percutaneous absorption of bromhexine in rats ${ }^{11)}$ and oestradiol in rabbits, ${ }^{12)}$ respectively. The percutaneous absorption of diltiazem and hydromorphone are also aided by some sugar esters. ${ }^{13,14)}$

Nakada et al. examined the effect of more than 10 sugar esters with HLB ranging 2 to 16 on the absorption of calcitonin from oral mucosa in rats. $\left.{ }^{8}\right)$ An enhancing effect was found for sugar esters with HLB values ranging from 11 to 16. However, the effect of the length of the fatty acid chain and HLB of sugar esters on their activity as percutaneous absorption enhancers has not been reported.

In the present study, we selected six sugar esters with HLB 5-16 and evaluated their effect on percutaneous drug permeation in in vitro experiments using excised hairless mouse skin. We employed lidocaine ( $\left.\mathrm{LC}, \mathrm{p} K_{\mathrm{a}}=7.9\right)^{15)}$ and ketoprofen $\left(\mathrm{KP}, \mathrm{p} K_{\mathrm{a}}=4.0\right)^{16)}$ as model basic and acidic drugs, respectively. The drugs were dissolved in buffer solutions with several $\mathrm{pHs}$ so that we could evaluate the effect of the sugar esters on the percutaneous permeation of ionized and unionized drug species.

It has been reported that sugar esters form micelles in water and in an organic solvent. ${ }^{17)}$ The micelles would affect the thermodynamic properties of a penetrant in a vehicle. To examine the effect of sugar esters on skin permeability and to minimize the effect on vehicle or interaction with drug in the vehicle, we employed the pretreatment technique. ${ }^{18)}$ Excised hairless mouse skin was pretreated with sugar esters to allow them penetrate into the skin. Then an LC or KP solution with no sugar esters was applied to evaluate the drug permeation rate. In the next set of experiments, we applied drug solutions or suspensions containing selected sugar esters to the excised skin with no pretreatment to evaluate the effect of sugar esters formulated in a vehicle on skin permeability.

\section{MATERIALS AND METHODS}

Materials Lidocaine (LC) and ketoprofen (KP) were obtained from Nagase ChemteX Co., Ltd. (Osaka, Japan) and 
Table 1. Sucrose Fatty Acid Esters Examined as Percutaneous Absorption Enhancers $^{a)}$

\begin{tabular}{crccc}
\hline \hline & & & \multicolumn{2}{c}{ Ester composition (\%) } \\
\cline { 4 - 5 } Sugar ester & HLB & $\begin{array}{c}\text { Fatty acid } \\
\text { composition (\%) }\end{array}$ & $\begin{array}{c}\text { Mono } \\
\text { ester }\end{array}$ & $\begin{array}{c}\text { Di-, tri-, and } \\
\text { polyesters }\end{array}$ \\
\hline J-1205 & 5 & $\mathrm{C} 12=100$ & 32 & 68 \\
J-1216 & 16 & $\mathrm{C} 12=100$ & 81 & 19 \\
J-1616 & 16 & $\mathrm{C} 16 / \mathrm{C} 18=80 / 20$ & 79 & 21 \\
J-1805 & 5 & $\mathrm{C} 16 / \mathrm{C} 18=30 / 70$ & 30 & 70 \\
J-1807 & 7 & $\mathrm{C} 16 / \mathrm{C} 18=30 / 70$ & 41 & 59 \\
$\mathrm{~J}-1816$ & 16 & $\mathrm{C} 16 / \mathrm{C} 18=30 / 70$ & 75 & 25 \\
\hline
\end{tabular}

a) Data communicated personally from Mitsubishi-Kagaku Foods Co.

Sigma Chemical Co. (St. Louis), respectively. The six sucrose fatty acid esters (Surfhope ${ }^{\circledR}$ SE Pharma) listed in Table 1 were kindly supplied by Mitsubishi-Kagaku Foods Co. (Tokyo, Japan). Propylene glycol (Nacalai Tesque, Kyoto, Japan) and the other reagents used were of analytical grade.

Solution Preparation Sugar esters were dissolved in an admixture of acetone and ethanol $(3: 2)$ at a concentration of $0.25 \mathrm{w} / \mathrm{v} \%$. This solvent was employed because a preliminary study revealed that the acetone/ethanol admixture was a better solvent for all of the six sugar esters than the other solvents examined.

LC and KP were dissolved in $0.01 \mathrm{M}$ citrate buffer solution to prepare $0.2 \% \mathrm{LC}$ solution $(\mathrm{pH} 6)$ and $0.2 \% \mathrm{KP}$ solution ( $\mathrm{pH}$ 6). LC was dissolved in $0.01 \mathrm{M}$ glycine buffer solution to prepare $0.05 \%$ LC solution $(\mathrm{pH} 10)$. KP was dissolved in water, the $\mathrm{pH}$ of which was adjusted to 2 by adding $1 \mathrm{M} \mathrm{HCl}$

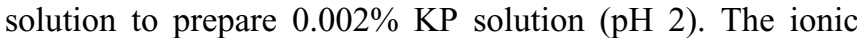
strength of these solutions was adjusted to 0.1 by the addition of $\mathrm{NaCl}$. The amounts of $\mathrm{NaCl}$ to be added were calculated using the computer program reported elsewhere. ${ }^{19)}$

When the drugs were dissolved in propylene glycol, the concentration was fixed at $5 \%$.

In Vitro Permeation Study through Excised Hairless Mouse Skin The full-thickness dorsal skin of female hairless mice ( $6-8$ weeks), sacrificed by cervical dislocation, was excised and adherent fat and other visceral debris were removed from the undersurface. Four pieces of the skin samples were obtained per animal. The freshly excised skin was mounted on a flow-through type diffusion cell made of teflon so that the stratum corneum faced upright. The effective diffusion area was $1 \mathrm{~cm}^{2}$. The diffusion cells were maintained at $37^{\circ} \mathrm{C}$ in a water bath throughout the experiment. The receptor cell $(1 \mathrm{ml})$ was washed continuously with phosphatebuffered saline ( $\mathrm{pH} \mathrm{7.4)} \mathrm{with} \mathrm{a} \mathrm{flow} \mathrm{rate} \mathrm{of} \mathrm{about} 5 \mathrm{ml} / \mathrm{h}$.

To examine the direct effects of the sugar esters on skin permeability, the surface of skin samples mounted on the diffusion cells was pretreated with $0.1 \mathrm{ml}$ each of the $0.25 \mathrm{w} / \mathrm{v} \%$ sugar ester solutions. The donor cells were open to air to allow the solvent to evaporate and let the sugar esters penetrate into the skin. The acetone/ethanol admixture with no sugar esters was applied to the skin for control experiments. Two hours later, $0.5 \mathrm{ml}$ of a drug solution was applied to the skin. The donor cells were closed to prevent the water vehicle from evaporating. The volume of the closed donor cells was $1 \mathrm{ml}$. The receptor fluid was collected every hour for $6 \mathrm{~h}$ after the application of drug solutions.

In another set of experiments, we applied $0.5 \mathrm{ml}$ of a drug

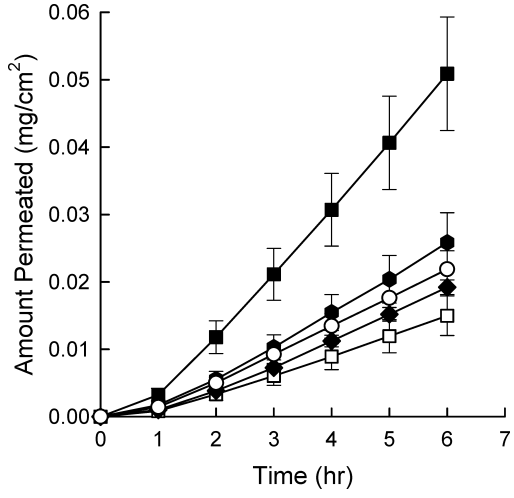

Fig. 1. Permeation Profiles of LC from a pH 6 Buffer Solution through the Excised Hairless Mouse Skin Pretreated with No Sugar Esters (O), J-1205 $(\square), \mathrm{J}-1216(\square), \mathrm{J}-1616(\bullet)$, or J-1816 (•)

The error bars indicate S.E. for $3-4$ experiments.

solution or suspension containing selected sugar esters to the excised skin with no pretreatment.

Determination of LC The LC concentrations in the samples obtained in penetration studies were determined using an HPLC system (LC-10AD, Shimadzu, Kyoto). A mobile phase composed of water, methanol, and phosphoric acid (79:20:1) was passed through a Cosmosil 5C18-AR column ( $5 \mu \mathrm{m}, 4.6 \times 150 \mathrm{~mm}$, Nacalai Tesque, Inc., Kyoto, Japan) at a rate of $1.2 \mathrm{ml} / \mathrm{min}$ at $36^{\circ} \mathrm{C}$. The injection volume was $10 \mu \mathrm{l}$. LC was detected from the UV absorbance at $220 \mathrm{~nm}$.

Determination of KP The same HPLC equipment as described above was used for the determination of KP. A mobile phase composed of methanol and $0.1 \%$ phosphoric acid solution $(65: 35)$ was passed through the Cosmosil 5C18-AR column at a rate of $1.0 \mathrm{ml} / \mathrm{min}$ at $36^{\circ} \mathrm{C}$. The injection volume was $10 \mu \mathrm{l}$. LC was detected from the UV absorbance at $264 \mathrm{~nm}$.

Determination of Permeation Rate and Permeability Coefficient The permeation rates $\left(\mathrm{mg} / \mathrm{cm}^{2} / \mathrm{h}\right)$ of LC and $\mathrm{KP}$ were calculated from the slope of the linear portion of the permeation-time profiles. At least three consecutive data points were used to make a regression calculation. The apparent permeability coefficient was obtained by dividing the permeation rate by the drug concentration in the applied solution.

Statistical Analysis The permeability coefficient determined for the skin pretreated with a sugar ester was compared statistically with that for the control skin using oneway ANOVA followed by least significant difference test. The significance level was set at $p<0.05$.

\section{RESULTS}

Effect of Pretreatment of Skin with Sugar Esters on Permeation of LC The permeation of LC through the excised hairless mouse skin pretreated with a sugar ester was examined. Typical permeation profiles are shown in Fig. 1. Figure 2 shows the permeability coefficient of LC applied with the pH 6 buffer solution. Most of LC (98.8\%) is ionized at this $\mathrm{pH}$. The skin pretreated with J-1216 showed a significantly increased permeability coefficient of LC at pH 6 while the effect of the other sugar esters examined was not significant. 


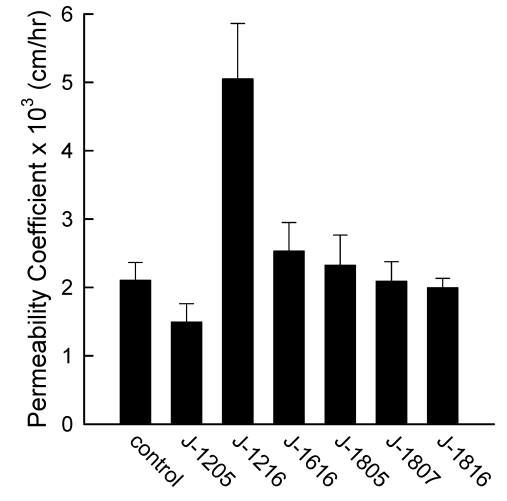

Fig. 2. Permeability Coefficient of LC Applied with a pH 6 Buffer Solution to the Excised Hairless Mouse Skin Pretreated with Sugar Esters

The error bars indicate S.E. for 3-4 experiments. Statistical difference was observed between $\mathrm{J}-1216$ and all the other groups.

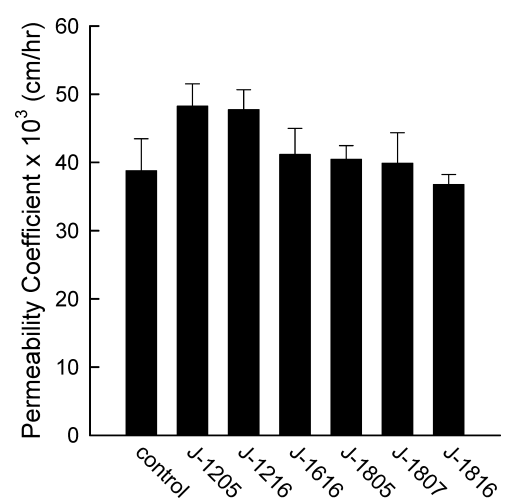

Fig. 3. Permeability Coefficient of LC Applied with a pH 10 Buffer Solution to the Excised Hairless Mouse Skin Pretreated with Sugar Esters

The error bars indicate S.E. for 3-4 experiments. Statistical difference was observed for (J-1205 vs. J-1816) and (J-1216 vs. J-1816).

We applied $0.5 \mathrm{ml}$ of $0.2 \% \mathrm{LC}$ solution to the skin pretreated with $0.1 \mathrm{ml}$ of the $0.25 \%$ sugar ester solutions. If all the sugar esters redissolved in the applied LC solution, the concentration should be $0.05 \%$. We examined the effect of $0.05 \% \mathrm{~J}-1216$ formulated in a $0.2 \%$ LC solution on the permeability of LC through the skin without pretreatment. The permeability coefficient with $0.05 \% \mathrm{~J}-1216$ was $0.00136 \pm 0.00024 \mathrm{~cm} / \mathrm{h}$, which was not statistically different from the control $(0.00119 \pm 0.00011 \mathrm{~cm} / \mathrm{h})$. This suggests that the increased permeability observed in the pretreatment experiment was caused by J-1216 in the skin.

No sugar esters enhanced LC permeation from the $\mathrm{pH} 10$ solution (Fig. 3), in which $99.2 \%$ of LC was unionized.

J-1205 increased the permeability coefficient of LC applied with propylene glycol two-fold significantly (Fig. 4).

Effect of J-1205 and J-1216 Formulated in Various Vehicles on Permeation of LC The pretreatment experiments revealed that J-1216 and J-1205 were candidate enhancers for LC in the $\mathrm{pH} 6$ buffer solution and propylene glycol, respectively. In the next series of experiments, we formulated $1.5 \%$ of $\mathrm{J}-1205$ and $\mathrm{J}-1216$ in various vehicles to examine their effect on the permeation of LC applied on the excised hairless mouse skin with no pretreatment. We employed aqueous LC suspensions at $\mathrm{pH} 7$ instead of at $\mathrm{pH} 6$ because the LC solubility at $\mathrm{pH} 6$ was too high to prepare suspensions. J-1216 increased the LC permeation from $\mathrm{pH} 7$ (0.01 M phosphate buffer) suspension significantly, while $\mathrm{J}$ -

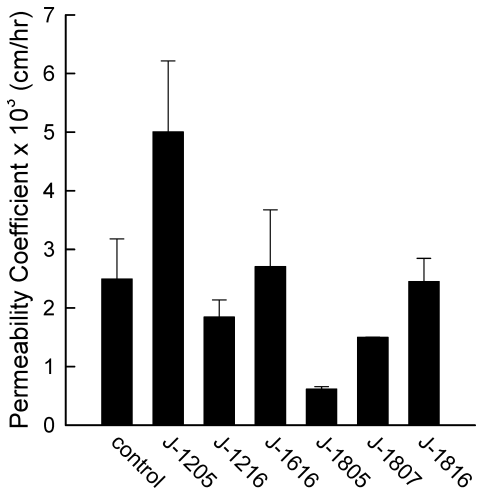

Fig. 4. Permeability Coefficient of LC Applied with a Propylene Glycol Solution to the Excised Hairless Mouse Skin Pretreated with Sugar Esters

The error bars indicate S.E. for 3-4 experiments. Statistical difference was observed between J-1205 and all the other groups except for J-1616.

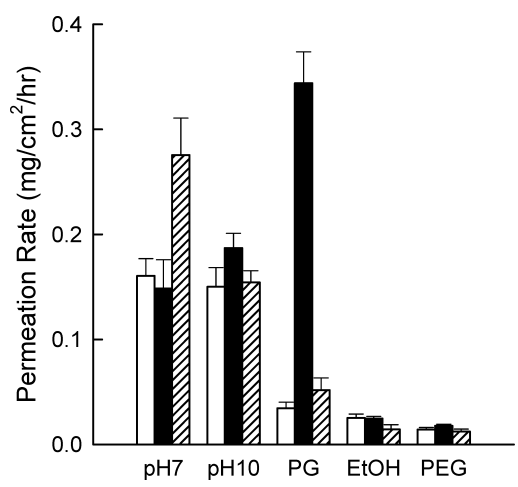

Fig. 5. Permeation Rate of LC Applied with Various Vehicles Containing No Sugar Ester (Left), 1.5\% J-1205 (Middle), or 1.5\% J-1216 (Right) through the Excised Hairless Mouse Skin

LC was suspended in $\mathrm{pH} 7$ and $\mathrm{pH} 10$ buffer solutions and dissolved in propylene glycol (PG), ethanol (EtOH), and polyethylene glycol 400 (PEG) at 5\%. The error bars indicate S.E. for $4-6$ experiments. Statistical difference was observed between J-1216 and the other two groups at $\mathrm{pH} 7$ and $\mathrm{J}-1205$ and the other two groups with PG.

1216 in $\mathrm{pH} 10$ suspension and $\mathrm{J}-1205$ in $\mathrm{pH} 7$ and 10 suspensions did not work as penetration enhancers (Fig. 5). J-1205 was effective to increase LC permeation from 5\% LC solution in propylene glycol. These finding coincided with the results of the pretreatment experiment, and the effect of J-1205 in propylene glycol was more remarkable than that observed in the pretreatment study. J-1205 and J-1216 did not affect the permeation of LC from ethanol and polyethylene glycol 400 .

Effect of Sugar Esters on Permeation of KP The results obtained for LC suggested that J-1216 and J-1205 would increase drug absorption from aqueous and propylene glycol vehicles, respectively. We next examined the permeation of KP, an acidic drug, through the skin pretreated with these two sugar esters. $99.1 \%$ of $\mathrm{KP}$ is ionized at $\mathrm{pH} 6$ and $98.9 \%$ of $\mathrm{KP}$ is unionized at $\mathrm{pH} 2$. The increase in the permeability coefficient of KP applied with the aqueous vehicles by the sugar esters was only slight (Fig. 6). J-1216 did not increase permeation of the ionized KP as the case of LC. When KP was applied with propylene glycol, J-1205 increased the permeability coefficient significantly.

When these sugar esters were dissolved in propylene glycol at $1.5 \%, \mathrm{~J}-1205$ increased significantly the KP permeation rate (Fig. 7). The KP permeation from 5\% KP solution in propylene glycol with J-1205 was much faster than that 
from aqueous KP suspension ( $\mathrm{pH}$ 3.8), suggesting that the combination of J-1205 and propylene glycol would be a potent vehicle for transdermal formulations.

\section{DISCUSSION}

The stratum corneum is a lipophilic membrane that acts as a strong barrier especially to hydrophilic or ionized drugs. However, it has been recognized that in some cases there is significant permeation of ionized drugs through the skin. Hadgraft and Valenta analyzed the solubility and permeation properties of ibuprofen and lidocaine through human skin as a function of $\mathrm{pH}^{20)}$ They concluded that the maximum flux through the skin may occur at a $\mathrm{pH}$ where ionization of the drugs is high since the aqueous solubility of the ionized species is significantly higher than that of the unionized species. Francoeur et al. examined the permeation rate of piroxicam from $50 \%$ ethanol vehicles containing $0.25 \%$ oleic acid as an absorption enhancer. ${ }^{21)}$ Although piroxicam was suspended in the vehicles, the flux was increased by an increase in the $\mathrm{pH}$ of solution, which resulted in an increase in the solubility, more precisely, the concentration of ionized piroxicam. If permeation through the skin were only a function of neutral drug concentration, changes in the vehicle $\mathrm{pH}$ should produce little or no effect on the transport. Because the effect of sugar esters depended on the $\mathrm{pH}$ of the aqueous vehicles in the present study, it would be worth while examining the permeability of unionized and ionized LC and KP.

The apparent permeability coefficient $\left(k p_{\text {app }}\right)$ through the

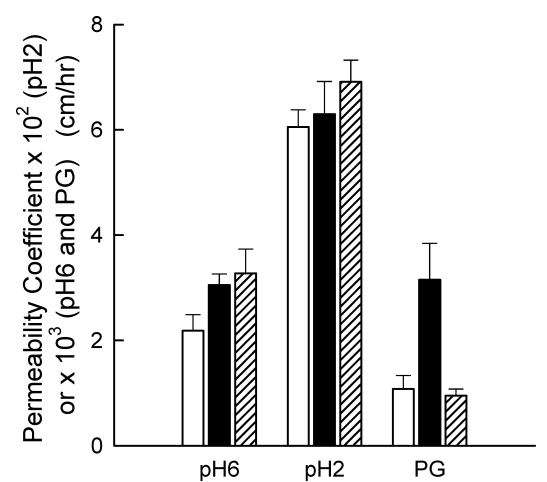

Fig. 6. Permeability Coefficient of KP Applied with a pH 6 Buffer Solution, $\mathrm{pH} 2$ Buffer Solution, or PG Solution through the Excised Hairless Mouse Skin Pretreated with No Sugar Esters (Left), J-1205 (Middle), or J1216 (Right)

The error bars indicate S.E. for 3-4 experiments. Statistical difference was observed between J-1205 and the other two groups with PG. skin, which are illustrated in Figs. 2, 3, and 6, can be expressed as

$$
k p_{\text {app }}=k p_{\text {ion }} \times f_{\text {ion }}+k p_{\text {union }} \times f_{\text {union }}
$$

where $k p_{\text {ion }}, k p_{\text {union }}, f_{\text {ion }}$, and $f_{\text {union }}$ are the permeability coefficients of the ionized and unionized species and the respective fractions. The ionized fractions are 0.9876 for $\mathrm{LC}\left(\mathrm{p} K_{\mathrm{a}}=7.9\right)$ at $\mathrm{pH} 6,0.0079$ for $\mathrm{LC}$ at $\mathrm{pH} 10,0.9905$ for $\mathrm{KP}\left(\mathrm{p} K_{\mathrm{a}}=4.0\right)$ at $\mathrm{pH}$ 6, and 0.0104 for $\mathrm{KP}$ at $\mathrm{pH} 2$. The unionized fractions are obtained by subtracting the corresponding ionized fraction from 1 . The permeability coefficients $k p_{\text {ion }}$ and $k p_{\text {union }}$ for LC and KP through the skin pretreated with a sugar ester were calculated by solving the simultaneous equations obtained by putting $k p_{\text {app }}, f_{\text {union }}$, and $f_{\text {ion }}$ at $\mathrm{pHs} 6$ and 10 for $\mathrm{LC}$ and $\mathrm{pHs} 6$ and 2 for KP in Eq. 1 and are listed in Table 2.

It should be noted that the permeability coefficient of ionized drugs listed in Table 2 would be affected by the effect of pretreatment with acetone/ethanol. The permeability coefficient of LC from $\mathrm{pH} 6$ solution through the skin pretreated with the acetone/ethanol admixture $(0.00213 \pm 0.00030 \mathrm{~cm} / \mathrm{h})$ was twice that through the skin with no pretreatment $(0.00119 \pm 0.00011 \mathrm{~cm} / \mathrm{h})$. While the permeability coefficient of LC from $\mathrm{pH} 10$ solution through the skin pretreated with the acetone/ethanol admixture $(0.0388 \pm 0.0048 \mathrm{~cm} / \mathrm{h})$ was comparable to that through the skin with no pretreatment $(0.0315 \pm 0.0027 \mathrm{~cm} / \mathrm{h})$. This suggests that the skin pretreated with the acetone/ethanol admixture would have higher permeability to the ionized drugs than the skin with no pretreatment.

The ionized LC and KP permeated even through the skin

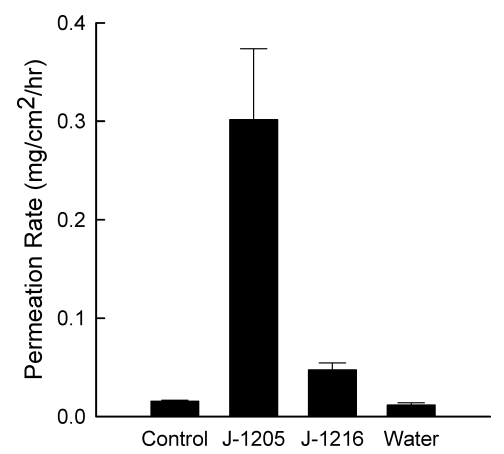

Fig. 7. Permeation Rate of KP Applied with Propylene Glycol (PG) Containing No Sugar Ester (Control), 1.5\% J-1205, or 1.5\% J-1216 and, Water through the Excised Hairless Mouse Skin

$\mathrm{KP}$ was dissolved in propylene glycol at $5 \%$ and suspended in water. The error bars indicate S.E. for $3-5$ experiments. Statistical difference was observed between J-1205 and the other two groups with PG. (Water was omitted from the statistical comparison.)

Table 2. Permeability Coefficient of Ionized and Unionized Species of LC and KP for Permeation through the Excised Hairless Mouse Skin Pretreated with Sugar Esters

\begin{tabular}{|c|c|c|c|c|}
\hline \multirow{2}{*}{ Sugar ester } & \multicolumn{4}{|c|}{ Permeability coefficient $\times 10^{3}(\mathrm{~cm} / \mathrm{h})$} \\
\hline & Ionized LC & Unionized LC & Ionized KP & Unionized KP \\
\hline None & 1.64 & 39.1 & 1.62 & 61.2 \\
\hline $\mathrm{J}-1205$ & 0.904 & 48.7 & 2.47 & 63.6 \\
\hline $\mathrm{J}-1216$ & 4.51 & 48.1 & 2.64 & 69.8 \\
\hline $\mathrm{J}-1616$ & 2.04 & 41.5 & $\mathrm{ND}^{a)}$ & ND \\
\hline $\mathrm{J}-1805$ & 1.84 & 40.8 & ND & ND \\
\hline $\mathrm{J}-1807$ & 1.61 & 40.2 & ND & ND \\
\hline $\mathrm{J}-1816$ & 1.56 & 37.1 & ND & ND \\
\hline
\end{tabular}


pretreated with vehicle only, although the permeability coefficients were 24 times and 38 times less than those of the unionized LC and KP, respectively. J-1216 remarkably increased (2.7 times) the permeability of ionized LC, while J1205 decreased it by half. J-1216 and J-1205 slightly increased the permeability coefficient of unionized LC while the other sugar esters examined showed no effect on the permeability of unionized LC. As for KP, J-1216 and J-1205 did not affect the permeability of unionized species while they increased the permeability of ionized species slightly $(1.5$ times). These results suggest that J-1216 is a candidate absorption enhancer for ionized LC. On the other hand, J-1205 is a candidate absorption enhancer for drugs formulated not in aqueous vehicle but in propylene glycol vehicle (Figs. 4, 6 ). The physicochemical properties of penetrants greatly affect the activity of absorption enhancers. ${ }^{22}$ We are now examining the effect of these sugar esters on the percutaneous permeation of a wide range of drugs.

When aqueous suspensions of LC were applied (Fig. 5), J1216 increased LC permeability at $\mathrm{pH} 7$; however, it did not work at $\mathrm{pH} 10 . \mathrm{J}-1205$ was not effective at both pHs. Because the thermodynamic activity of LC should be the same in the suspensions, J-1216 should affect the permeability of the skin at $\mathrm{pH}$ 7. The enhancing activity of J-1216 at $\mathrm{pH} 6$ was also observed with an LC solution. When a $0.2 \%$ LC solution with $1.5 \% \mathrm{~J}-1216$ was applied, the permeability coefficient $(0.00235 \pm 0.00057 \mathrm{~cm} / \mathrm{h})$ was almost twice that for the control $(0.00119 \pm 0.00011 \mathrm{~cm} / \mathrm{h})$. However, when a $0.05 \%$ LC solution with $1.5 \% \mathrm{~J}-1216$ at $\mathrm{pH} 10$ was applied, the permeability coefficient $(0.00347 \pm 0.00024 \mathrm{~cm} / \mathrm{h})$ was significantly lower than the control $(0.00722 \pm 0.00056 \mathrm{~cm} / \mathrm{h})$. The permeability coefficient with $1.5 \% \quad \mathrm{~J}-1205$ at $\mathrm{pH} \quad 10$ $(0.00416 \pm 0.00037 \mathrm{~cm} / \mathrm{h})$ was also significantly lower than the control. Because the permeation rate from the LC suspensions at $\mathrm{pH} 10$ was not affected by the sugar esters, the decreased LC permeability observed for LC solution could be attributed to decreased LC thermodynamic activity in the solutions. This suggests interaction of LC with the sugar esters in the $\mathrm{pH} 10$ solutions. Because the critical micelle concentration of $\mathrm{J}-1216$ is reportedly $0.05 \%$ in an aqueous solution, ${ }^{17)}$ it was likely $\mathrm{J}-1216$ formed micelles in a $1.5 \%$ solution to interact with unionized LC. We will report the effect of interaction of LC with J-1216 on the LC permeability in the following paper.

The present study examined six sugar esters and revealed that J-1216 and J-1205 having lauryl chain(s) as the lipophilic moiety act as percutaneous absorption enhancers. Most percutaneous absorption enhancers have a hydrophilic moiety and lipophilic moiety in their structures, to which the sucrose moiety and fatty acid chain(s) correspond, respectively. It is known that the length of the hydrophobic chain affects the activity of percutaneous absorption enhancers markedly. Some fatty acids increase skin permeability. Lauric acid was the most effective among C6 to $\mathrm{C} 18$ saturated fatty acids for enhancing the absorption of molsidomine from polyethylene glycol through rat skin in vivo. ${ }^{23)}$ Lauric acid was also the most effective among C7 to $\mathrm{C} 18$ saturated fatty acids for promoting naloxone permeation from polyethylene glycol through human skin in vitro. ${ }^{24)}$ The permeation of indomethacin from petrolatum through shed snake skin in vitro, ${ }^{25)}$ metronidazole from polyethylene glycol through human skin in vitro, ${ }^{26)}$ and naloxone from polyethylene glycol through human skin in vitro was increased by lauryl alcohol more than the other $\mathrm{C} 8$ to $\mathrm{C} 18$ alcohols. ${ }^{24)}$ The absorption of polyethylene glycol was also fastest with lauryl alcohol. ${ }^{26}$ Among the alkyl methyl sulfoxides with $\mathrm{C} 1$ to $\mathrm{C} 14$ alkyl chains, decylmethyl sulfoxide most markedly enhanced the permeation of sodium nicotinate through excised guinea pig skin. ${ }^{27)}$ Compounds with a hydrophilic moiety and an alkyl chain of around $\mathrm{C} 12$ seem to have high activity as percutaneous absorption enhancers. Kushla and Zatz examined the effect of $\mathrm{C} 10$ to $\mathrm{C} 18$ alkyl trimethyl ammonium halide on the permeation of LC through excised human skin. ${ }^{28)}$ Peak surfactant enhancement effects were seen at alkyl chain lengths of 12 or 14 carbons. A C12 or C14 alkyl chain may fold into an open coil with six carbon atoms in each winding to minimize the size and volume of the molecule. They considered that the coiled conformation promotes the organization of water around the hydrophobic chain and leads to enhanced migration into the skin and thus more interaction with the keratin filaments. J-1216, $81 \%$ of which consists of mono-lauryl ester, also had a percutaneous penetration enhancing activity as well as the $\mathrm{C} 12$ or $\mathrm{C} 14$ compounds mentioned above.

For drugs that mainly cross the intact stratum corneum, there are two micro-routes of entry, the polar or pore pathway and non-polar pathways. It is likely that for ionized drugs the polar or pore route is the main pathway during absorption. As penetrants become more non-polar, the non-polar route probably becomes more significant as a mode of transport. It may be reasonable to consider that the ionized LC and KP penetrate the stratum corneum through the polar or pore pathway. Eighty-one percent of J-1216, which increased the permeability of ionized LC and KP, consists of the monoester. J-1216 or sucrose mono-lauryl ester would be sufficiently hydrophilic to affect the polar or pore pathway.

It is known that hydrophobic absorption enhancers such as oleic acid and Azone interact with the lipids in the stratum corneum, and their enhancing effect is synergistically increased when combined with a diol such as polyethylene glycol. $^{29)} \mathrm{J}-1205$, which increased the permeation of unionized LC and KP from polyethylene glycol vehicle, is a hydrophobic surfactant with HLB $=5,68 \%$ of which consists of di-, tri-, or poly-esters. It is likely that J-1205 or sucrose di-, tri-, or poly-lauryl ester interacts more strongly with a lipophilic region in the stratum corneum compared to sucrose monolauryl ester. Although the activity of J-1205 seems not to be high enough to increase the drug permeation from aqueous vehicle, J-1205 is a novel absorption enhancer for drugs formulated in a propylene glycol-rich vehicle.

\section{CONCLUSIONS}

Absorption enhancing activity has so far been reported for sugar esters with HLB $=11$ to 16 . The present study revealed that sucrose laurates with $\mathrm{HLB}=5$ as well as $\mathrm{HLB}=16$ have activity as percutaneous absorption enhancers. J-1216, a sucrose lauryl ester with high HLB $(=16)$, increases the permeation of ionized lidocaine from an aqueous vehicle. On the other hand, J-1205, which has not previously been reported to be an absorption enhancer, with relatively low HLB $(=5)$ enhanced the permeation of lidocaine and ketoprofen 
from propylene glycol. The combination of J-1205 and propylene glycol would be a potent vehicle for transdermal formulations.

\section{REFERENCES}

1) Ryoto ${ }^{\circledR}$ Sugar Esters, Technical Information, Mitsubishi Kagaku Foods Corporation, Japan, 2000

2) Surfhope ${ }^{\circledR}$ SE Pharma, Technical Information, Mitsubishi Kagaku Foods Corporation, Japan, 1999.

3) Taki K., Machida R., Katayama K., Eur. Pat. Appl. EP 57, 462, 11 August, 1982.

4) Nishikido Y., Suzuki N., Jpn. Kokai Tokkyo Koho JP 60, 1346 825, 2 August, 1985.

5) Hasumi T., Kagaya S., Sonobe T., Jpn. Kokai Tokkyo Koho JP 63 39,822, 20 February, 1988.

6) Shizue Y., Kimura Y., Toda M., Masuda Y., PCT Int. Appl. WO 90 05,535, 31 May, 1990.

7) Ueda Y., Hata T., Kimura A., Kono Y., Jpn. Kokai Tokkyo Koho JP 02,101,020, 12 April, 1990.

8) Nakada Y., Awata N., Nakamichi C., Sugimoto I., J. PharmacobioDyn., 11, 395-401 (1988).

9) Nakada Y., Ikuta Y., Awata N., J. Pharm. Sci. Technol. Jpn., 49, 166173 (1999).

10) Ganem-Quintanar A., Quintanar-Guerrero D., Falson-Rieg F., Buri P., Int. J. Pharmaceut., 173, 203-210 (1998).

11) Ogiso T., Iwaki M., Tsuji S., Chem. Pharm. Bull., 39, 1609-1611 (1991).

12) Vermeire A., DeMuynck C., Vandenbossche G., Eechaut, W., Geert M. L., Remon J. P., J. Pharm. Pharmacol., 48, 463-467 (1996).
13) Sakai Y., Ebisawa H., Shishikura T., Ishikura T., Takahashi M., Hasegawa H., Jpn. Kokai Tokkyo Koho JP 62,132,828, 16 June, 1987.

14) Cheng Y. L., Gale R. M., Sugihara E., Sanders H. F., Eur. Pat. Appl. EP 280, 413, 31 August, 1988.

15) Siddiqui O., Roberts M. S., Polack A. E., J. Pharm. Pharmacol., 37, 732-735 (1985)

16) Avdeef A., Berger C. M., Brownell C., Pharm. Res., 17, 85-89 (2000).

17) Ayala-Bravo H. A., Quintanar-Guerrero D., Naik A., Kalia Y. N., Cornejo-Bravo J. M., Ganem-Quintanar A., Pharm. Res., 20, 12671273 (2003).

18) Okamoto H., Hashida M., Sezaki H., J. Pharm. Sci., 77, 418-424 (1988).

19) Okamoto H., Mori K., Ohtsuka K., Ohuchi H., Ishii H., Pharm. Res., 14, 299-302 (1997).

20) Hadgraft J., Valenta C., Int. J. Pharmaceut., 200, 243-247 (2000).

21) Francoeur M. L., Golden G. M., Potts R. O., Pharm. Res., 7, 621-627 (1990).

22) Okamoto H., Hashida M., Sezaki H., J. Pharm. Sci., 80, 39-45 (1991).

23) Yamada M., Uda Y., Chem. Pharm. Bull., 35, 3390-3398 (1987).

24) Aungst B. J., Rogers N. J., Shefter E., Int. J. Pharmaceut., 33, 225234 (1986).

25) Tsuzuki N., Wong O., Higuchi T., Int. J. Pharmaceut., 46, 19-23 (1988).

26) Moellgaard B., Hoelgaard A., Acta Pharmaceut. Suec., 20, 443-450 (1983).

27) Sekura D. L., Scala J., Adv. Biol. Skin, 12, 257-269 (1972).

28) Kushla G. P., Zatz J. L., J. Pharm. Sci., 80, 1079-1083 (1991).

29) Barry B. W., Int. J. Cosmet. Sci., 10, 281-293 (1988). 